\title{
Guidelines to Implement or Improve Syndromic Surveillance Systems
}

\author{
Sylvia Medina ${ }^{1}$, Marta Sala-Soler ${ }^{1}$, Duncan Cooper ${ }^{2}$, Mark Kanieff ${ }^{3}$, Céline Caserio- \\ Schonemann ${ }^{1}$, Céline Dupuy ${ }^{4}$, Alex Elliot ${ }^{5}$, Gillian Smith ${ }^{5}$, Anette Hulth ${ }^{6}$, Luise Muller ${ }^{7}$, \\ Alexandra Ziemann ${ }^{8}$ and Anne Fouillet*1
}

${ }^{1}$ DCAR French Institute for Public Health Surveillance (InVS), Saint Maurice, France; ${ }^{2}$ National Health Service, Leeds, United Kingdom; ${ }^{3}$ Istituto Superiore di Sanità, Rome, Iceland; ${ }^{4}$ French Agency for Food, Environmental and Occupational Health Safety, Lyon, France; ${ }^{5}$ Public health of England, Birmingham, United Kingdom; ${ }^{6}$ Smittskyddsinstitutet, Stockholm, Sweden; ${ }^{7}$ Statens Serum Institut, Copenhagen, Denmark; ${ }^{8}$ Dept. of International Health, School of Public Health and Primary Care (Caphri), Faculty of Health, Medicine and Life Sciences, Maastricht University, Maastricht, Netherlands

\section{Objective}

To present the Guidelines for implementing syndromic surveillance (SyS) systems at a national, regional or local level.

\section{Introduction}

Co-financed by the European Commission through the Executive Agency for Health and Consumers, the European Triple-S project (Syndromic Surveillance Survey, Assessment towards Guidelines for Europe) was launched in 2010 for a 3-year period [1]. It involves 24 organisations from 13 countries. The project's final purpose is to increase the European capacity for real-time surveillance and monitoring of the health burden of expected and unexpected health-related events.

Based on inventories of European SyS systems [2;3], eight country visits [4] and experts advice, the project has developed scientific guidelines that aim at providing scientific and technical guidance for the development and implementation of SyS systems for both human and animal health.

\section{Methods}

After a definition of what SyS is and its added value for public health surveillance, the guidelines are organised follows the order of the steps necessary for implementing a SyS system:

1/ Getting organized: determining of the surveillance needs and the purposes of the system, identifying key partners

2/ How to collect and prepare the data: available data sources and usual information, relation with data providers, technical information for data transmission, data management and quality

3/ How to analyse the data: syndromes definition, building of epidemiological indicators, statistical methods, investigation of alarms

4/ How to disseminate the findings to support public health action according to the different stakeholders: decision makers, retro-information for data providers, communication with media

5/ How to evaluate the system, based on CDC criteria.

This document is completed by other guidelines helping countries to choose the most suitable data source in terms of their objectives and available resources [5].

\section{Results}

These guidelines are original as they are intended for use by public-health professionals and epidemiologists who do human or animal-health surveillance as part of their work and want to develop or improve SyS systems.

The guidelines have been written to be a practical and user-friendly document: each section provides many concrete examples of existing systems in Europe, references to the international literature and ends with minimal requirements for EU comparability and a checklist highlighting the key messages to keep in mind for implementing the step.

\section{Conclusions}

The triple-S partners contribute to knowledge transfer by sharing their experience in SyS, enabling to increase the capacity for countries to implement their systems even with limited local resources. Whilst these guidelines will be particularly suited to European use, their main principles will also be valid elsewhere.

In our changing, complex environment which creates new emerging cross-border risks, the document provide a set of common standards that will help exchange and interpret syndromic alerts across Europe, complying with the International Health Regulation, and strengthening European health protection. The next step is to suggest a strategy for enabling comparability at the European level of reporting from national SyS systems.

\section{Keywords}

Triple-S European project; Guidelines; Syndromic surveillance; System implementation

\section{Acknowledgments}

On behalf of the Triple-S project consortium.

\section{References}

[1] Triple-S Project (Grant Agreement 2009.11.12) http://www.syndromicsurveillance.eu

[2] Conti S, Kanieff M, Rago G. et al. Inventory of Syndromic Surveillance Systems in Europe. Septembre 2012. http://syndromicsurveillance.eu/ images/stories/Inventory/deliverable_4_triple-s_inventory_report.pdf

[3] Dupuy C, Bronner A, Watson E, Wuyckhuise-Sjouke L et al. Inventory of veterinary syndromic surveillance initiatives in Europe (Triple-S project): current situation and perspectives.Prev Vet Med. 2013 Sep 1;111(3-4):220-9

[4] Ziemann A, Krafft T, Brand H, Sala Soler M, et al. Identifying good practice for syndromic surveillance in Europe - a comparative study based on site visits in eight countries. Eur J Public Health (2012) 22 (suppl 2):79. European Public Health Conference, 2012

[5] Ziemann A, Krafft T, Sala Soler M, Fouillet A, et al. Use of different data sources for syndromic surveillance in Europe. International Meeting on Emerging Diseases and Surveillance, 2013.

\section{*Anne Fouillet}

E-mail: a.fouillet@invs.sante.fr 